\title{
Synthesis of $N$-Substituted Indole Derivatives via PIFA-Mediated Intramolecular Cyclization
}

\author{
Yunfei Du, Renhe Liu, Gregory Linn, Kang Zhao* \\ College of Pharmaceuticals and Biotechnology, Tianjin University, 300072, P. R. China
}

Supporting Information 2

Page

${ }^{1} \mathrm{H}$ NMR and ${ }^{13} \mathrm{C}$ NMR spectra of $\mathbf{1 a - 1 j}$

$\mathrm{S} 1-\mathrm{S} 21$ 


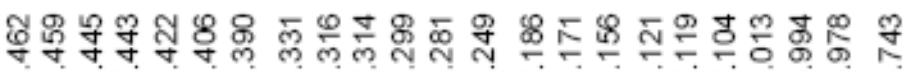

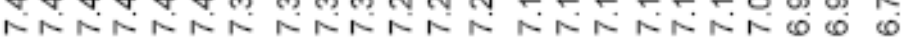

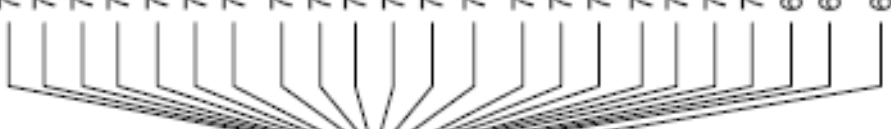

串

(i)

8

(1)<smiles>CC(Nc1ccccc1)=C(C#N)c1ccccc1</smiles>

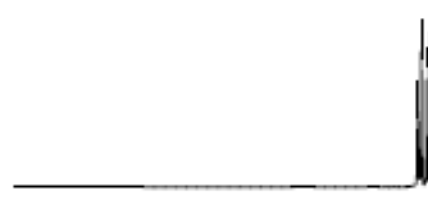

Wis

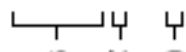

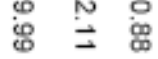

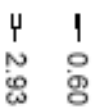

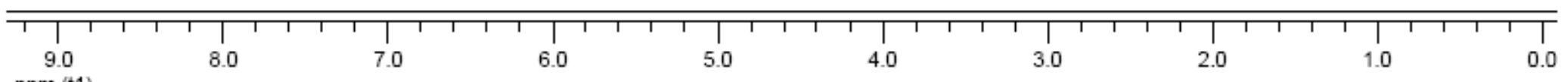

$\mathrm{ppm}(\mathrm{t} 1)$ 


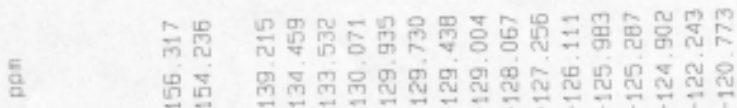

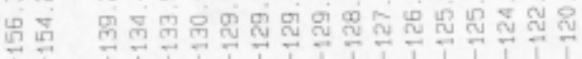
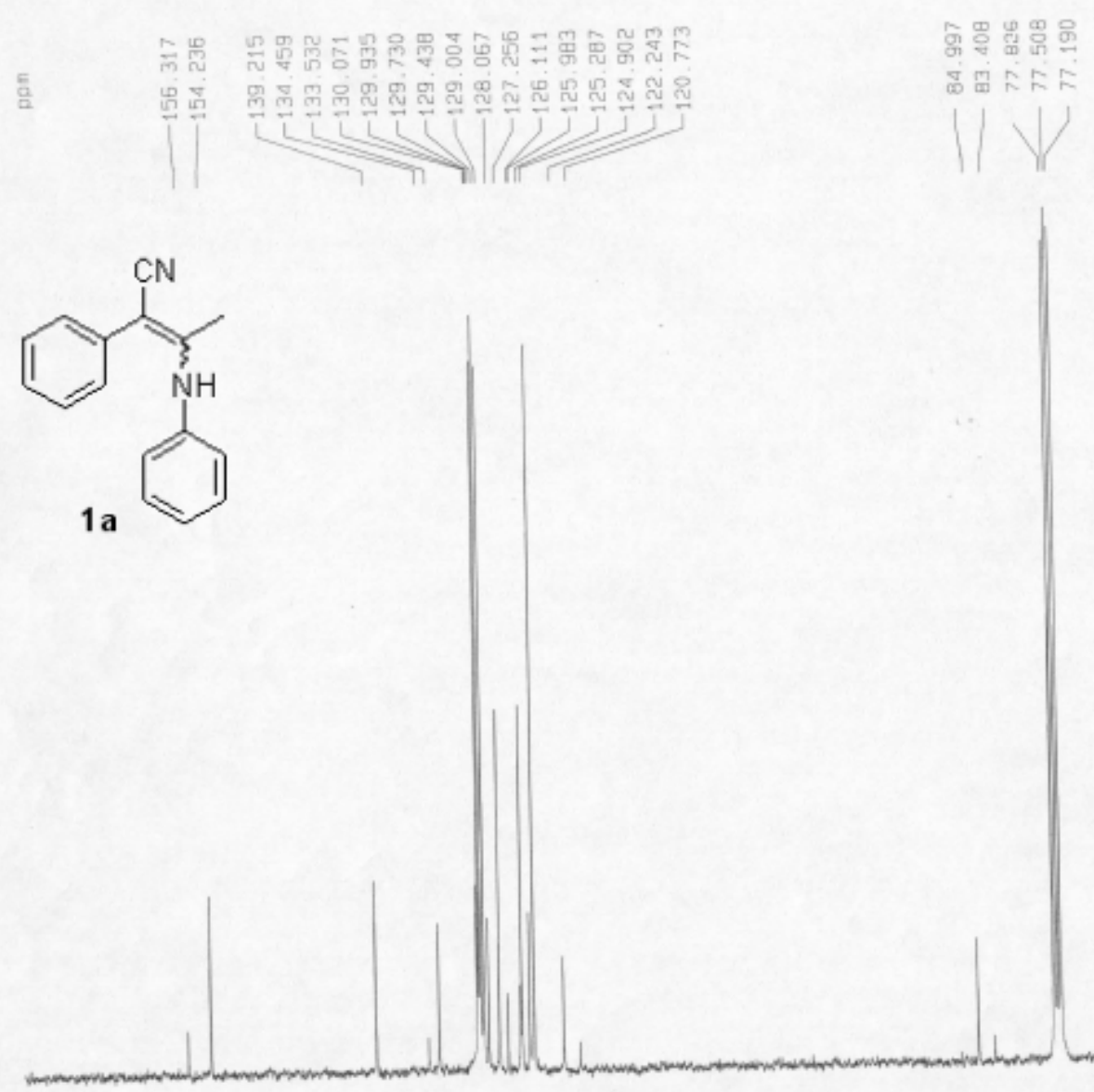

100

80

60

40

20 


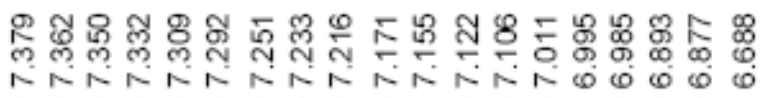

141.1<smiles>C/C(Nc1ccc(C)cc1)=C(\C#N)c1ccc(Cl)cc1</smiles>

零

:
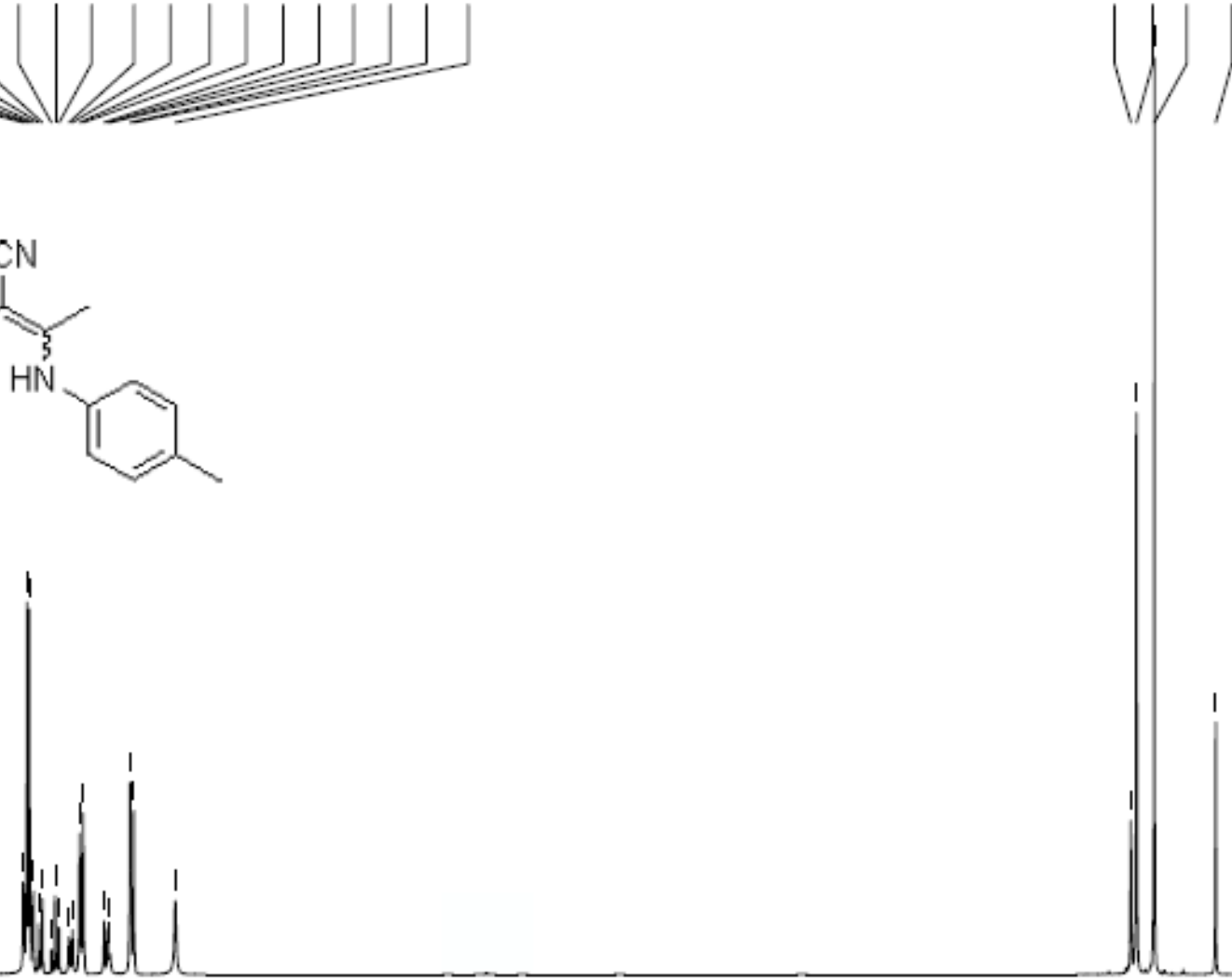

$\checkmark$, ب 나

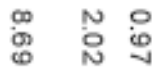

प4 4

एic

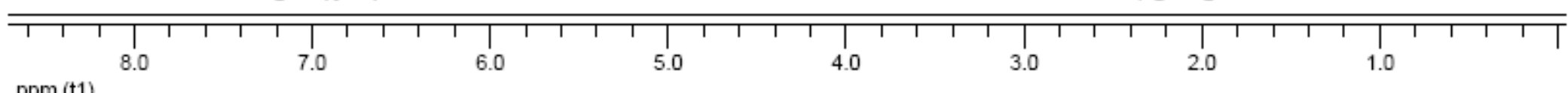

ppm (t1) 


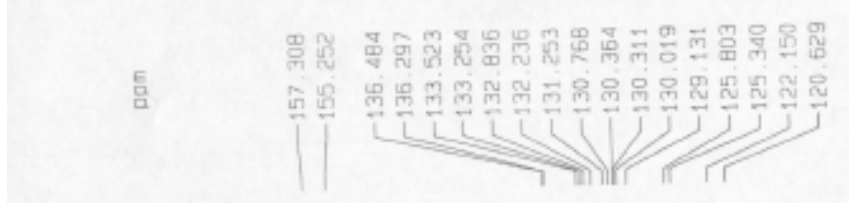

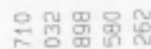

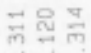

लू

IH

두의
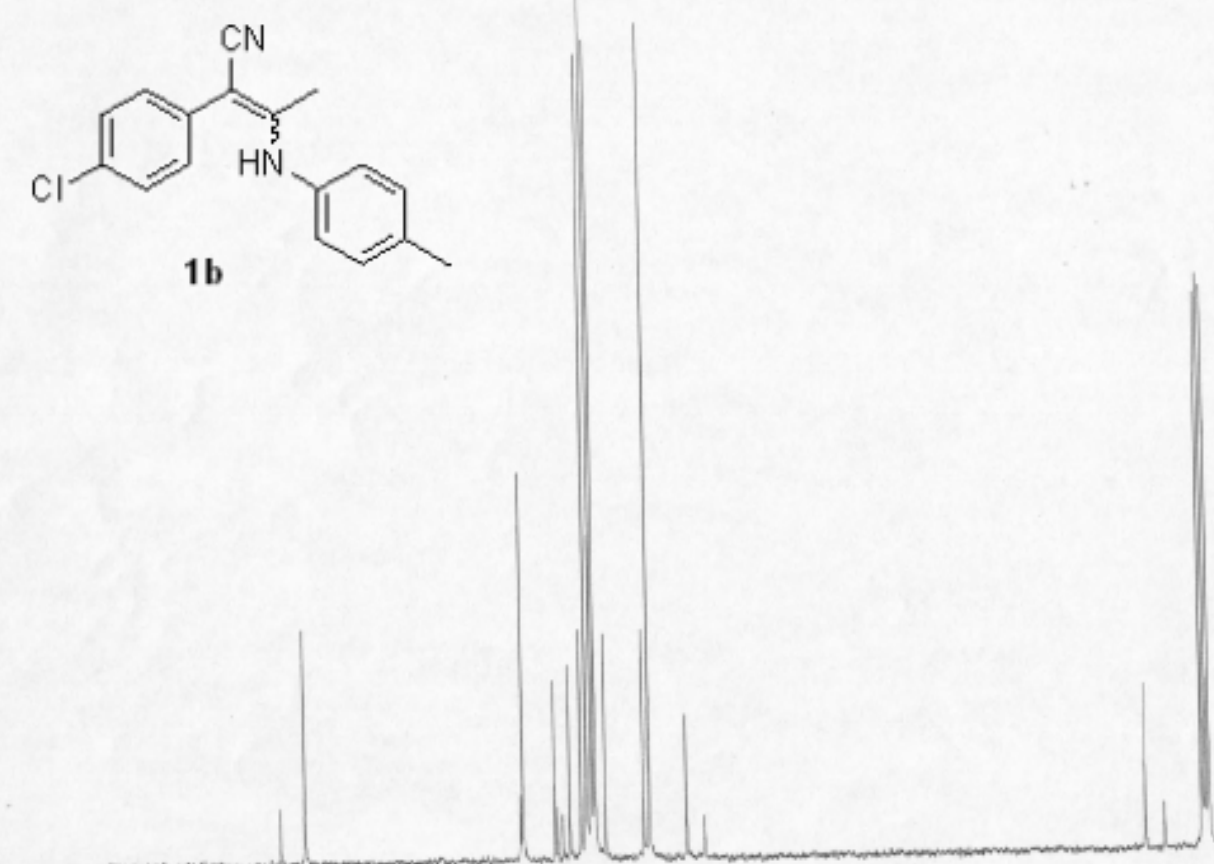

1
1
$0 p m \quad 160$

140

120

100

80 

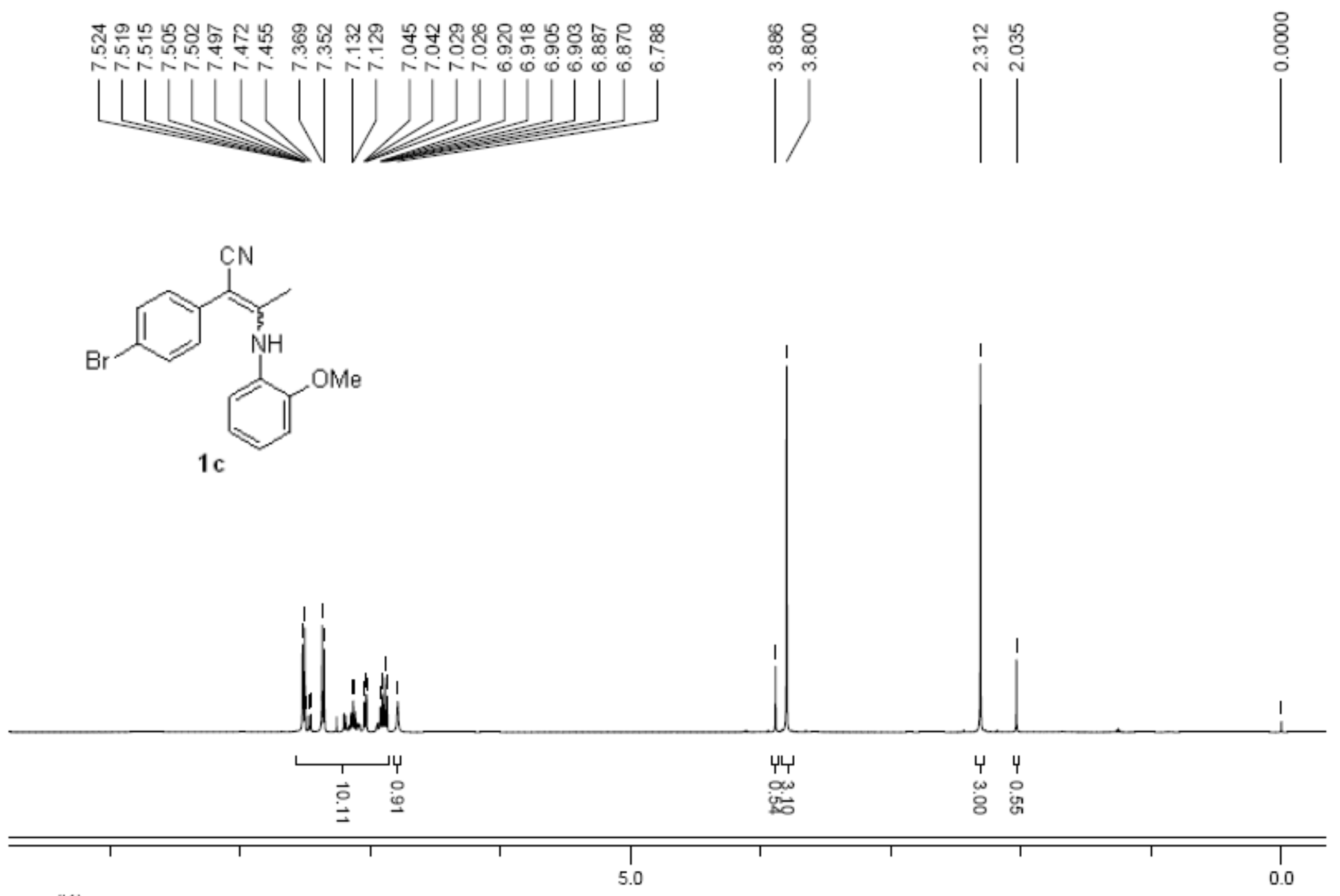

ppm (t1) 


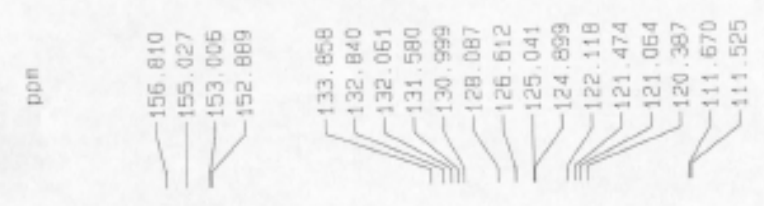

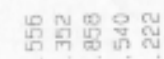

M

IV
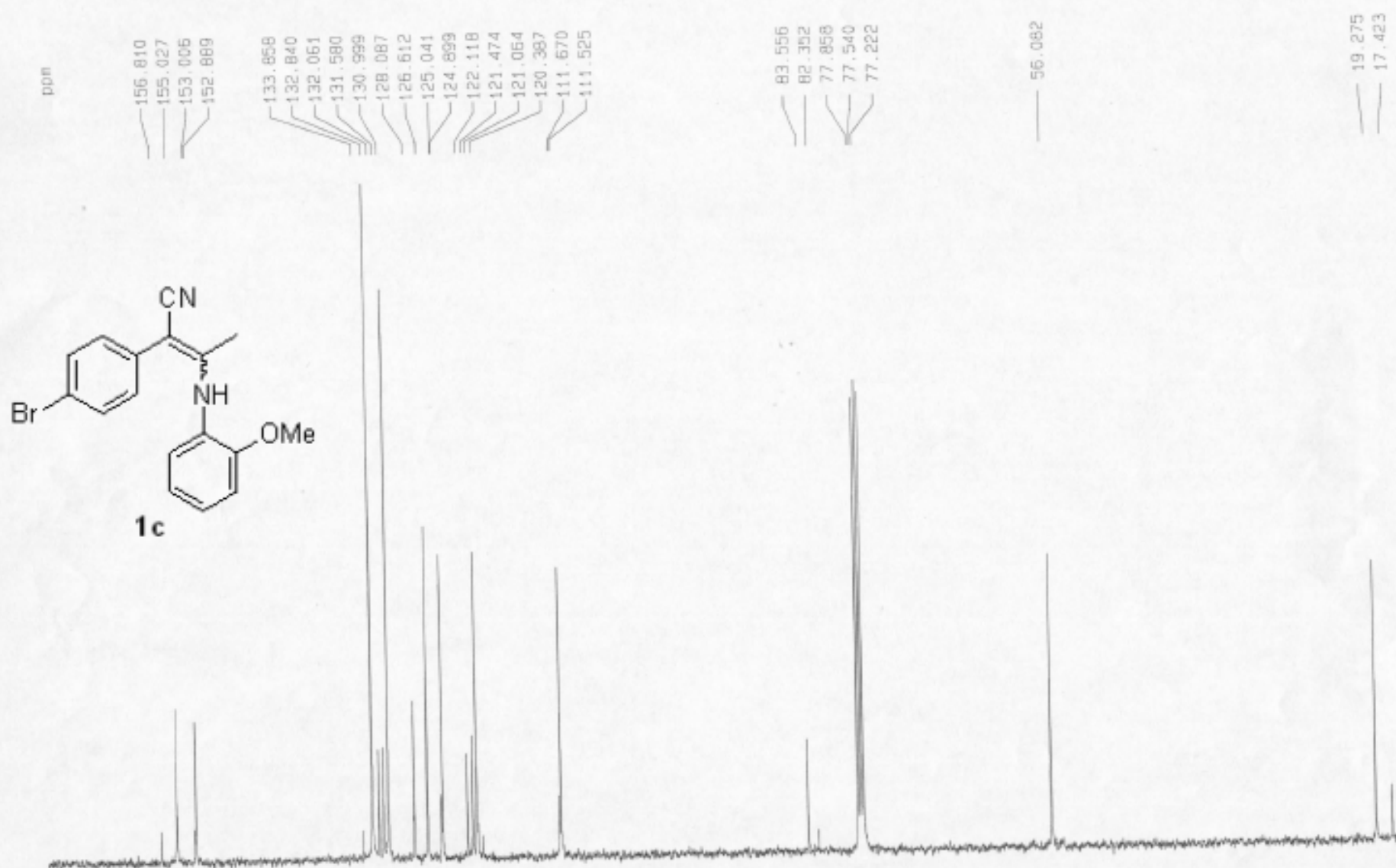


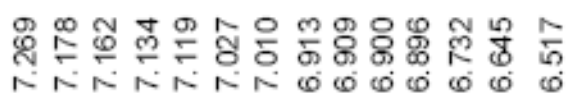

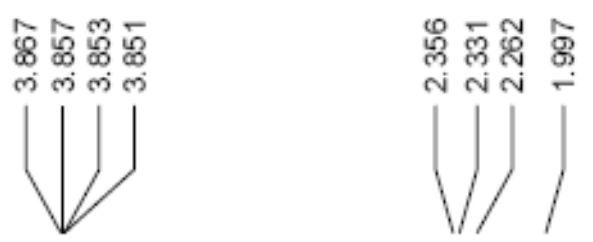

8
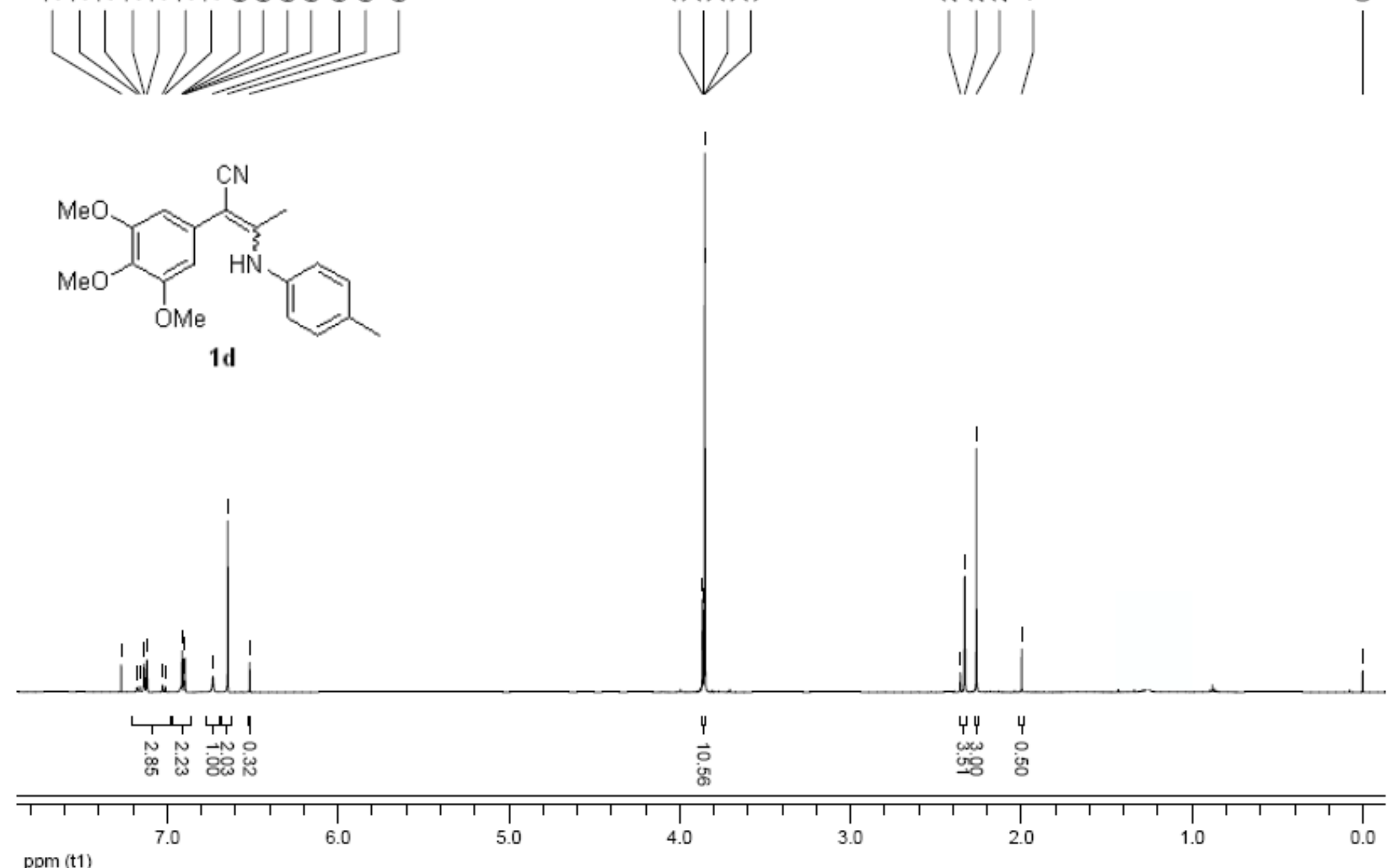
$d y f-1 d$

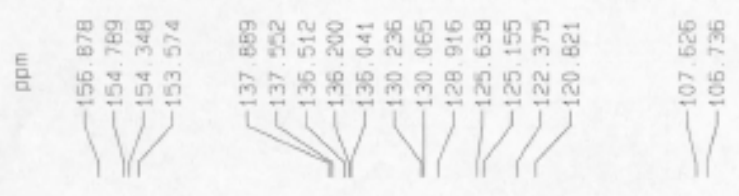
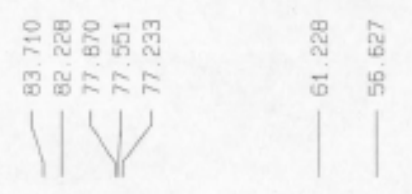

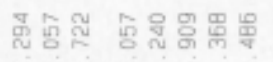

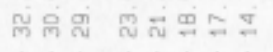<smiles>COc1cc(/C(C#N)=C(/C)Nc2ccc(C)cc2)cc(OC)c1OC</smiles>
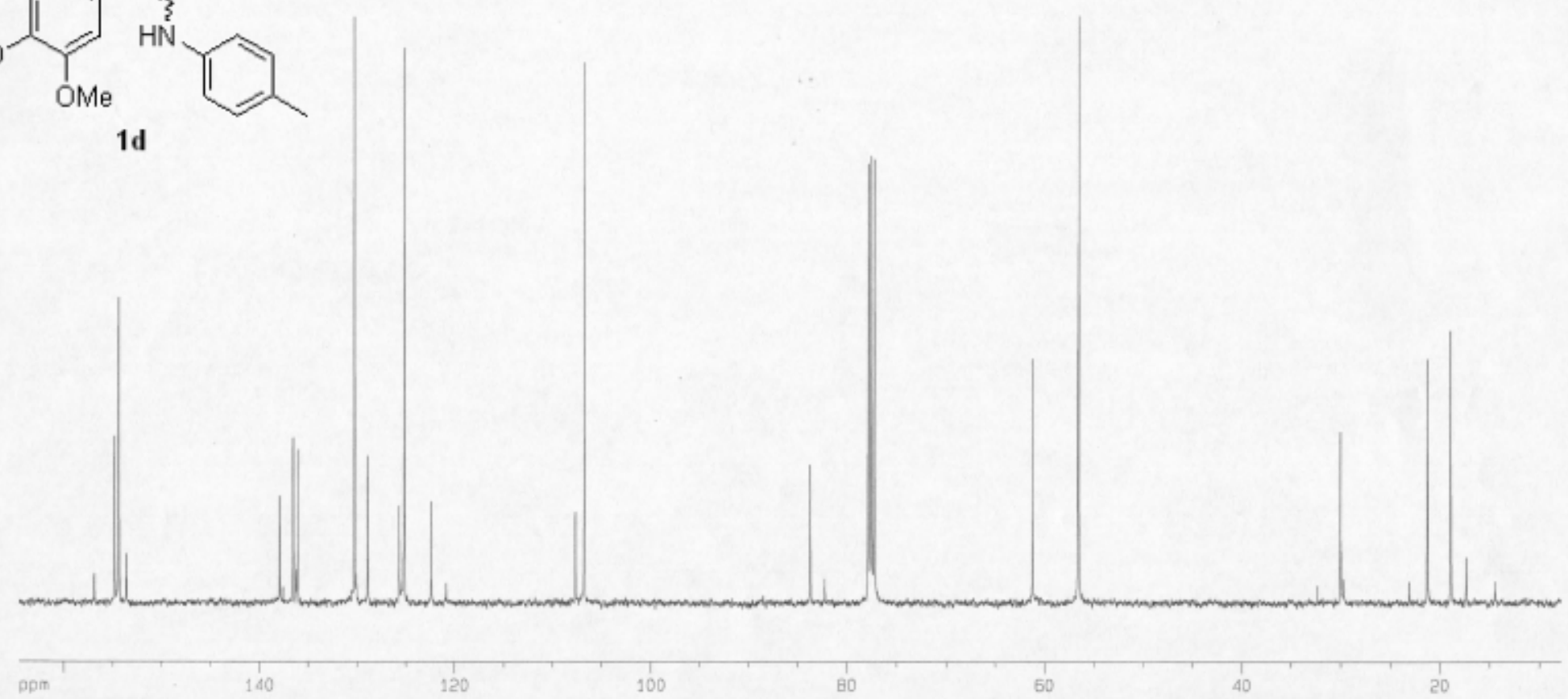

120

100

80

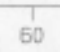

20

S9 


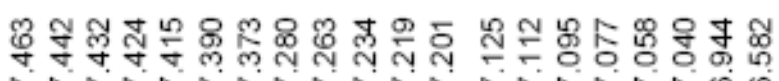

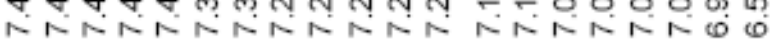

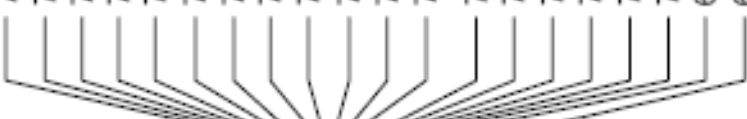

\&

ㄱ․

8<smiles>CC(Nc1ccccc1Cl)=C(C#N)c1ccc(F)cc1</smiles>

$1 \mathrm{e}$

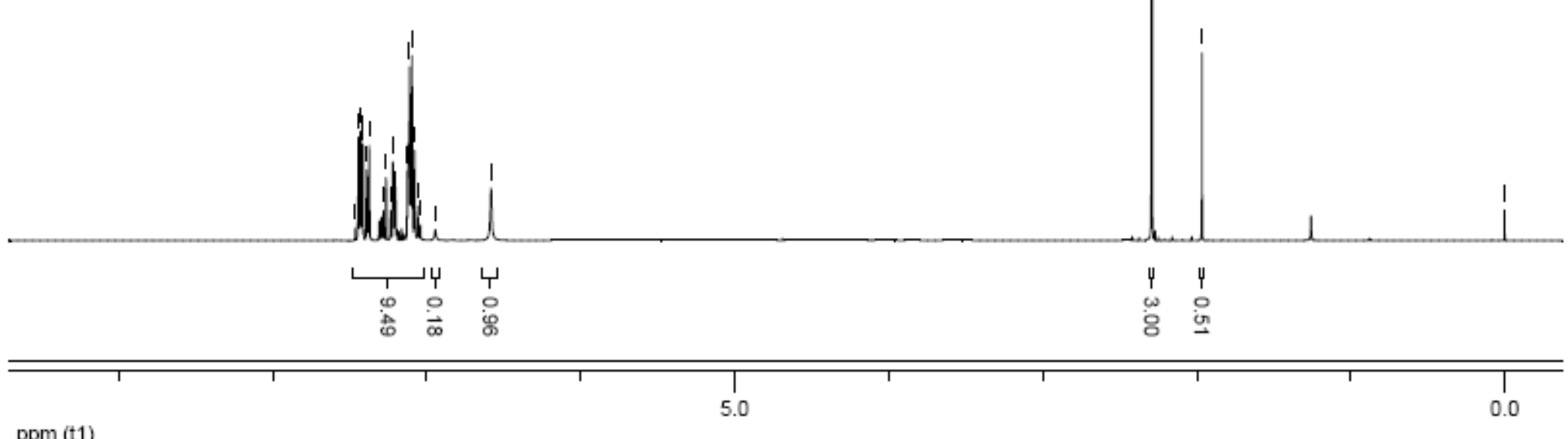



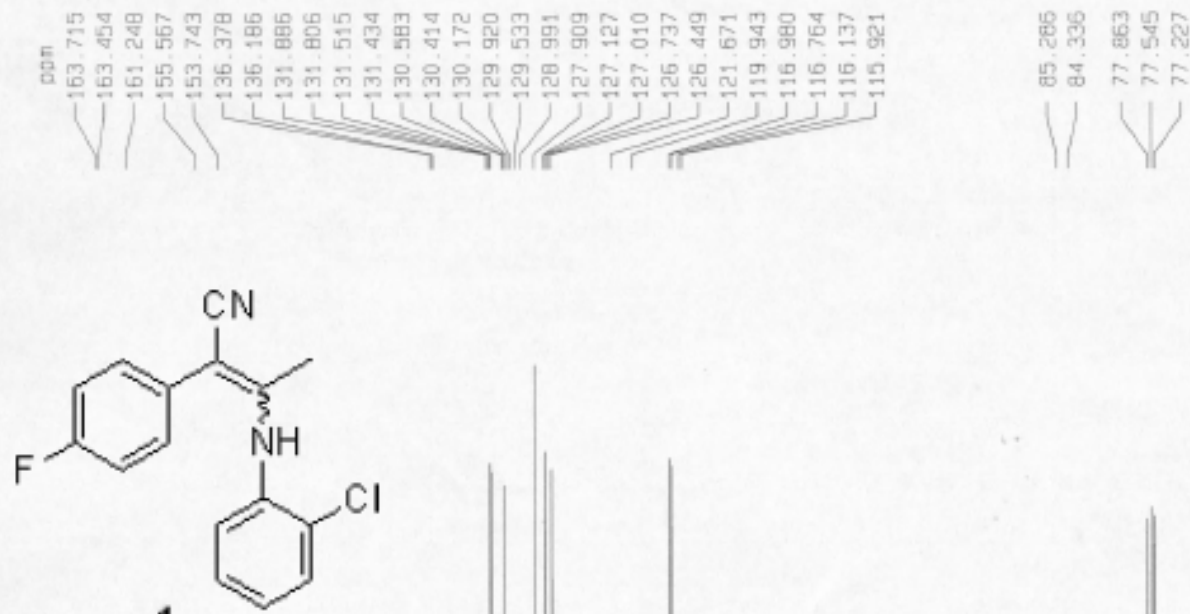

$1 \mathrm{e}$
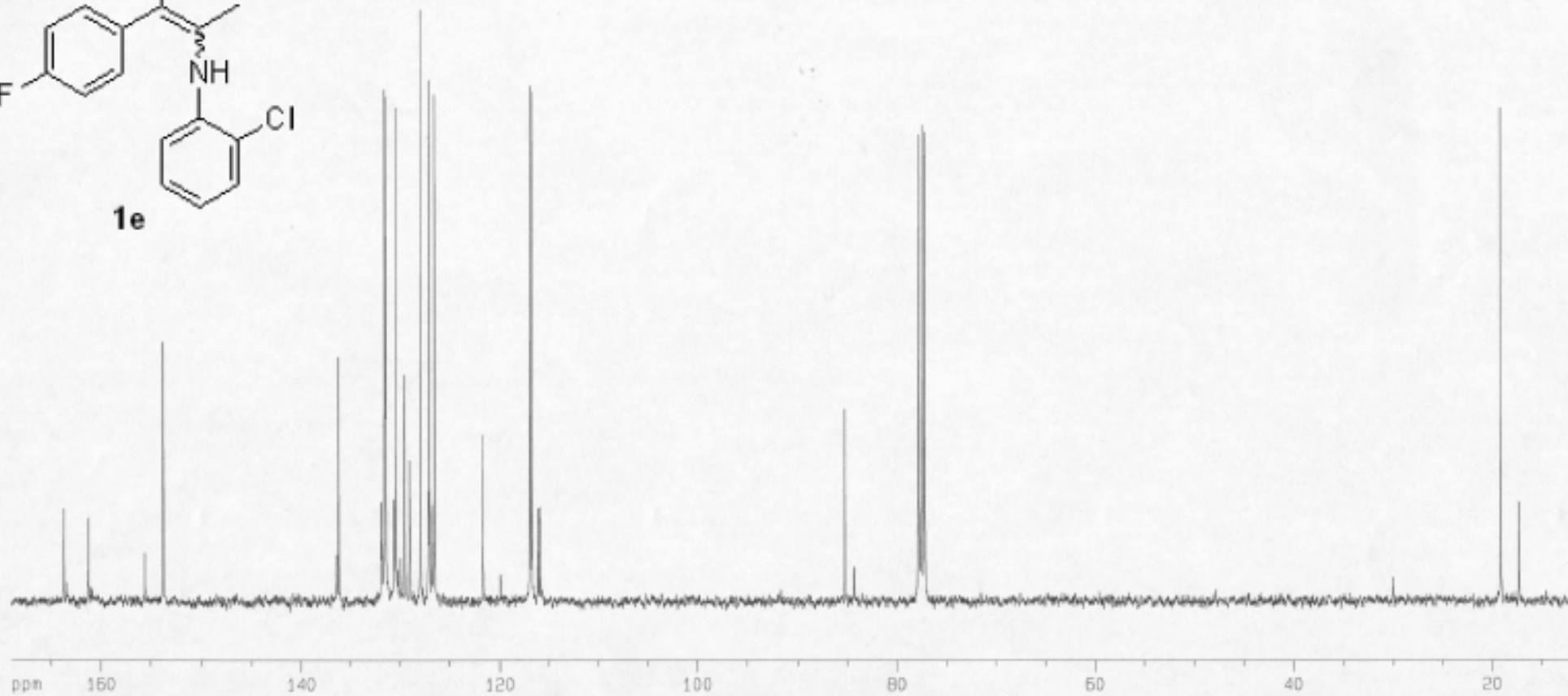


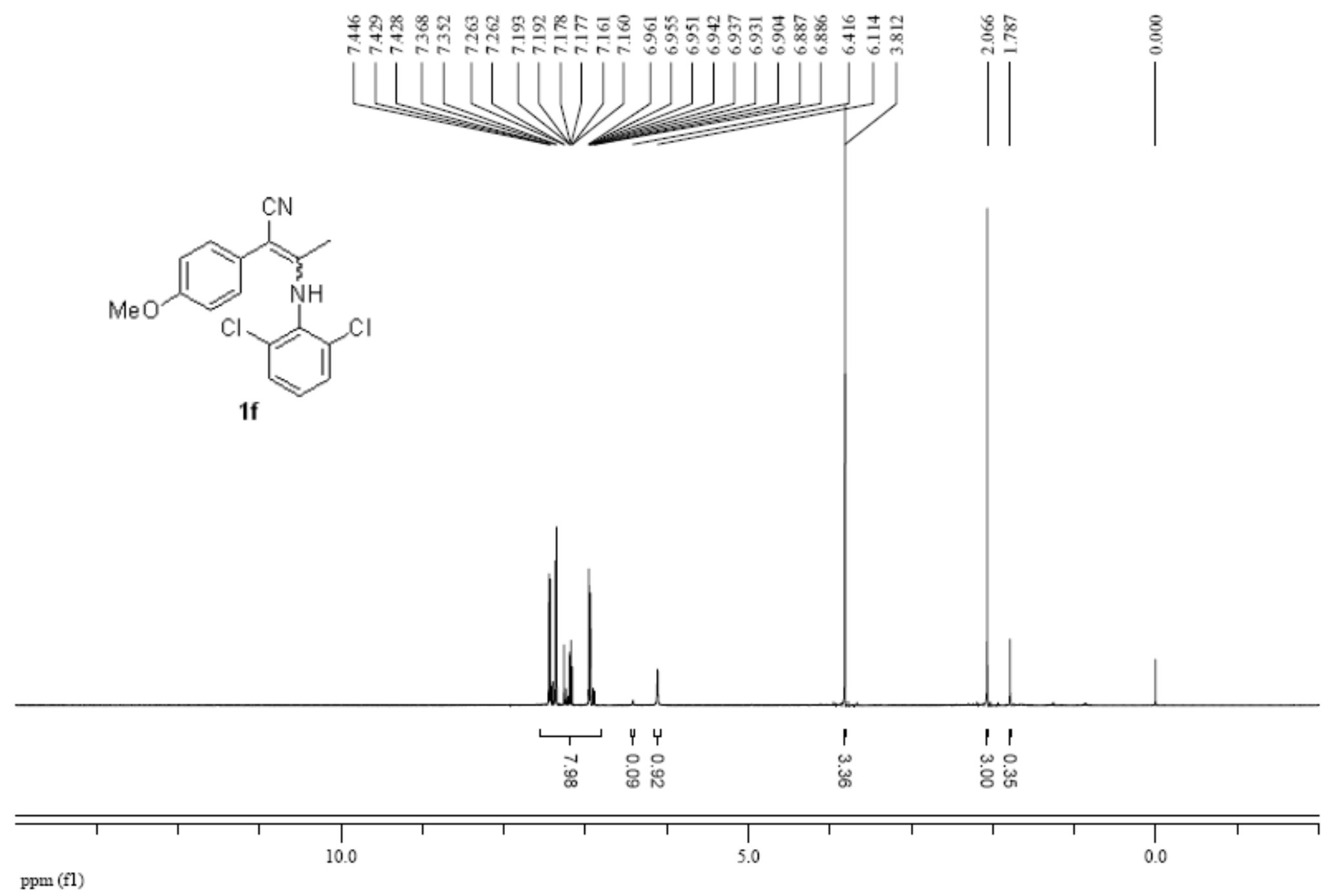


長

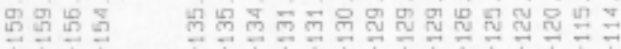

Vi
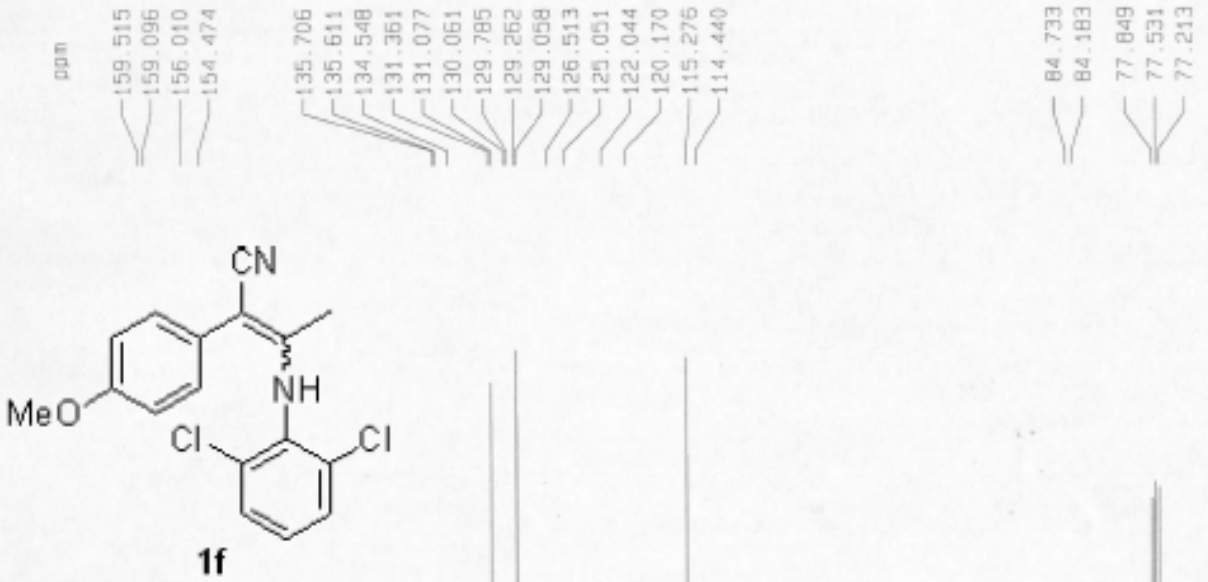


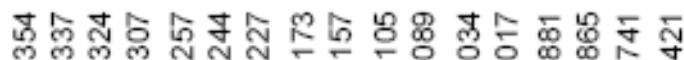

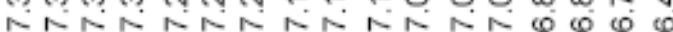

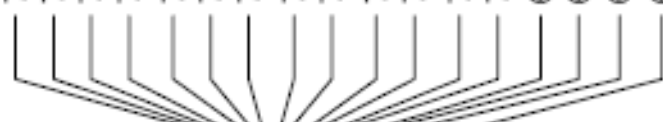

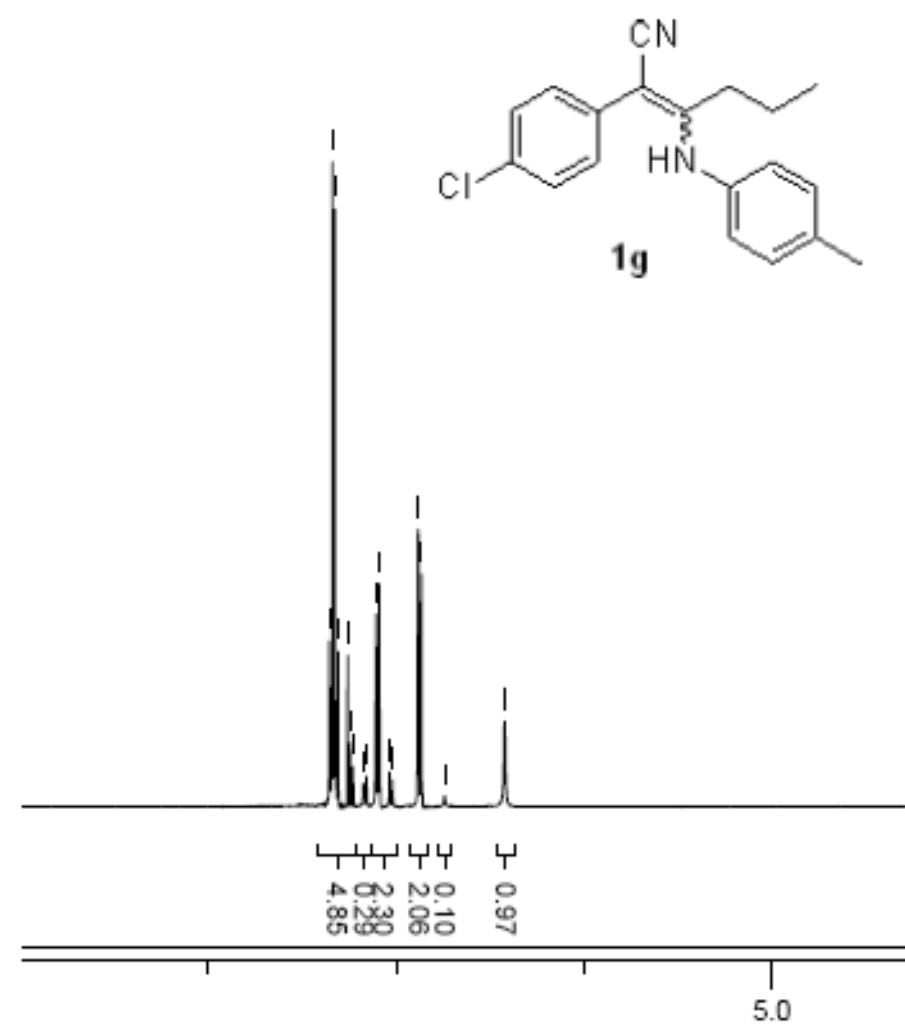

ppm (t1) \%
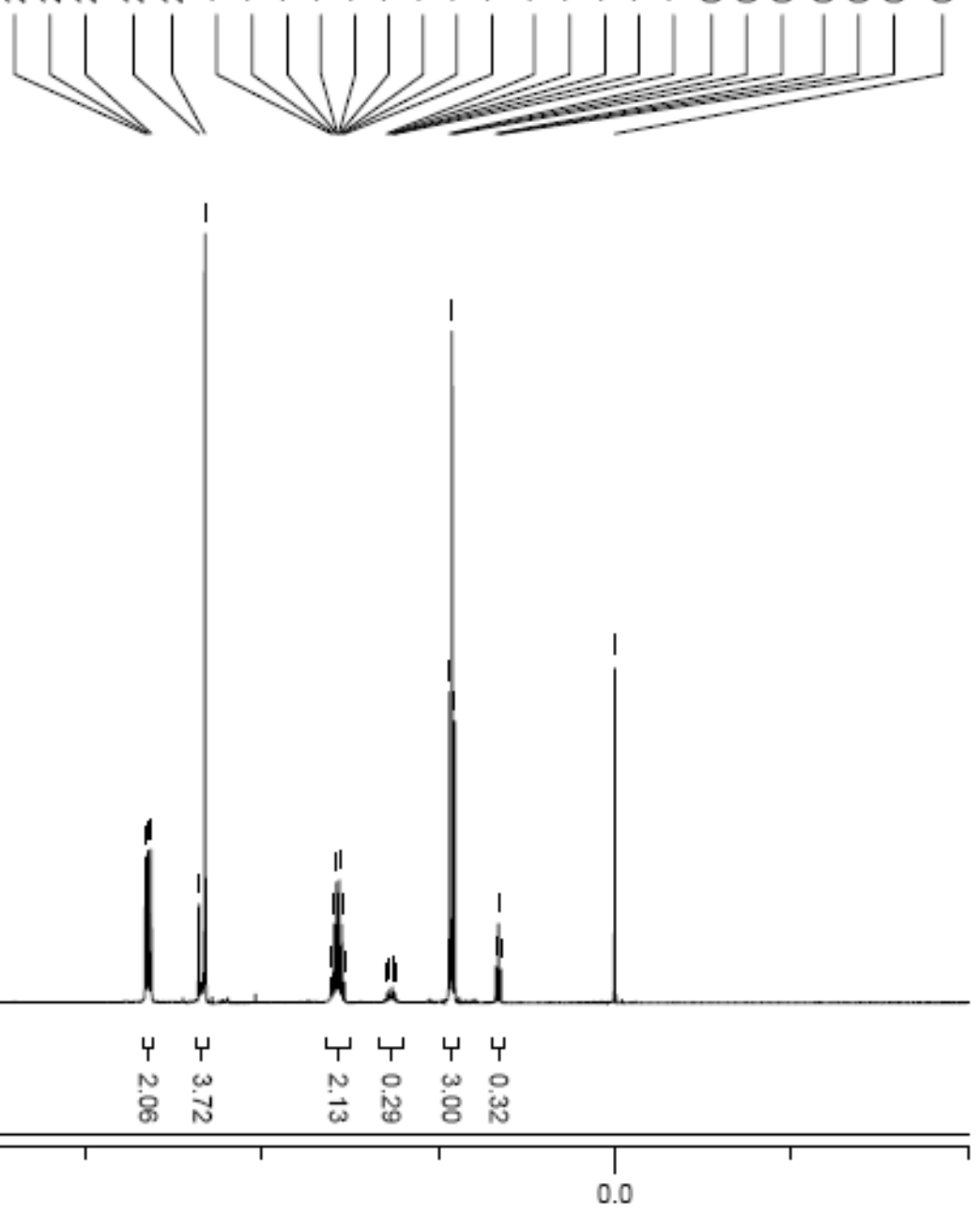

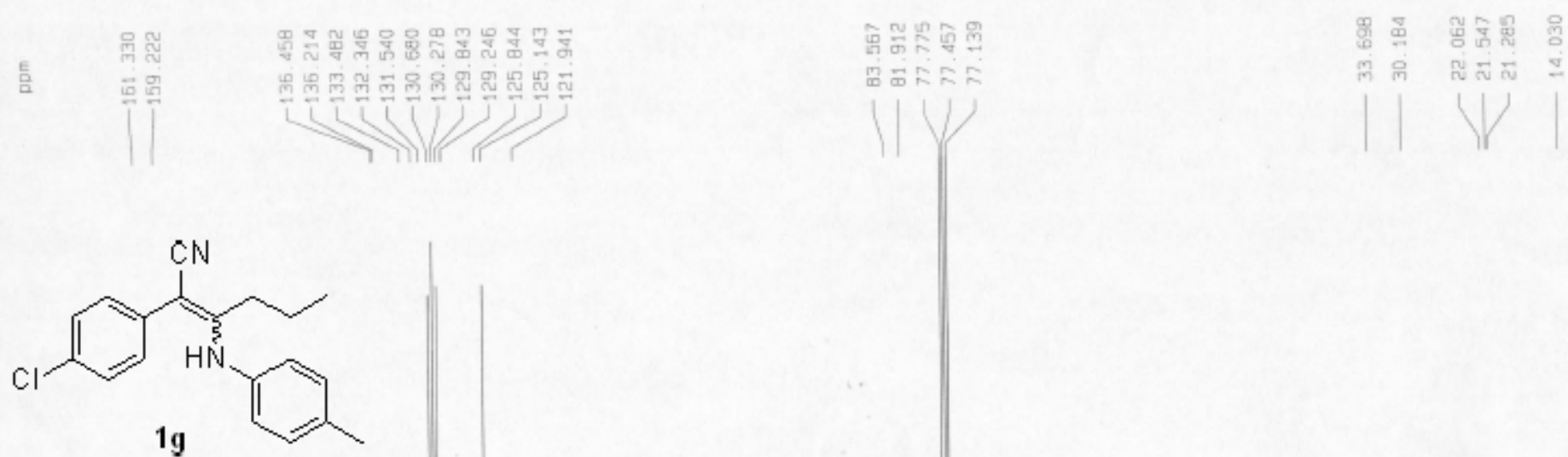

19
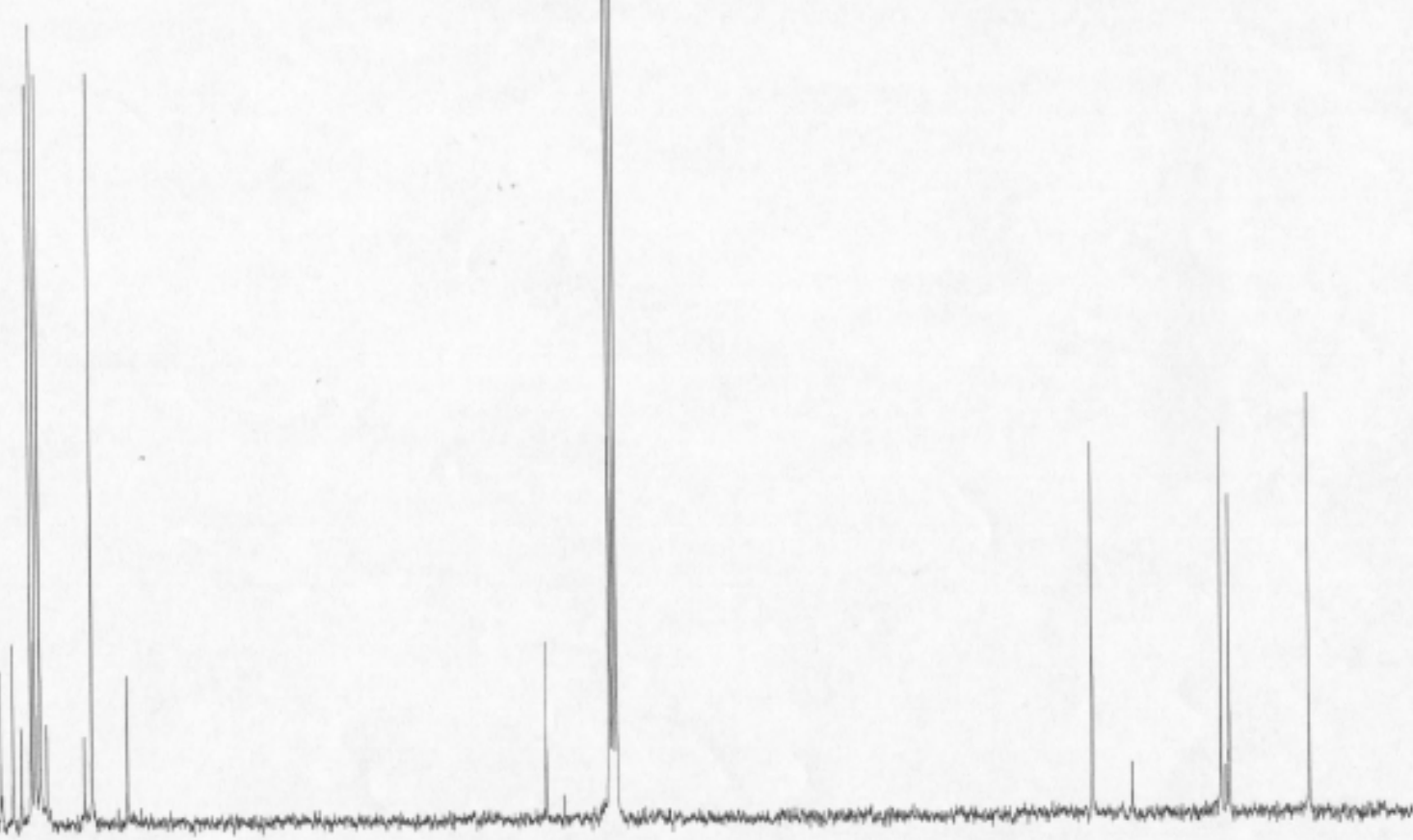

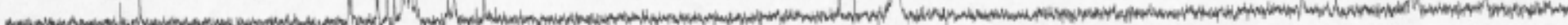

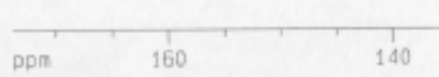

120

BD

60

40 
Љ

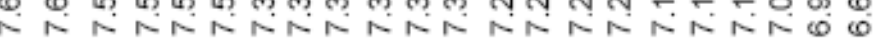

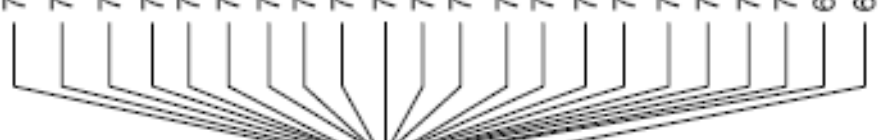<smiles>CC(Nc1ccccc1)=C(C#N)c1cccc(C(F)(F)F)c1</smiles>

$1 \mathrm{~h}$

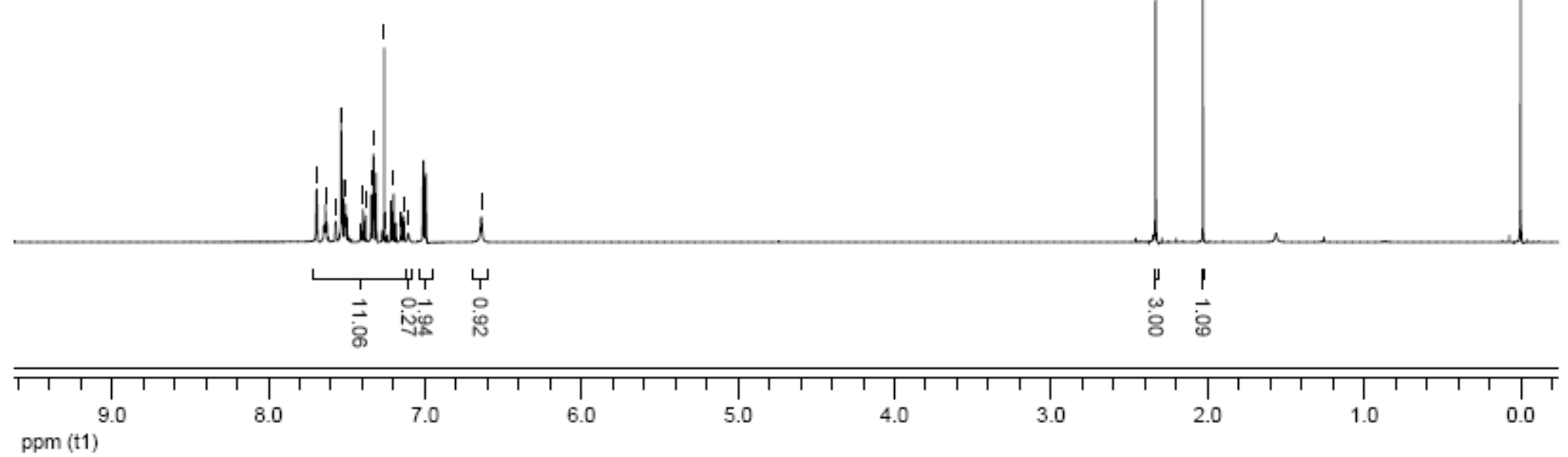



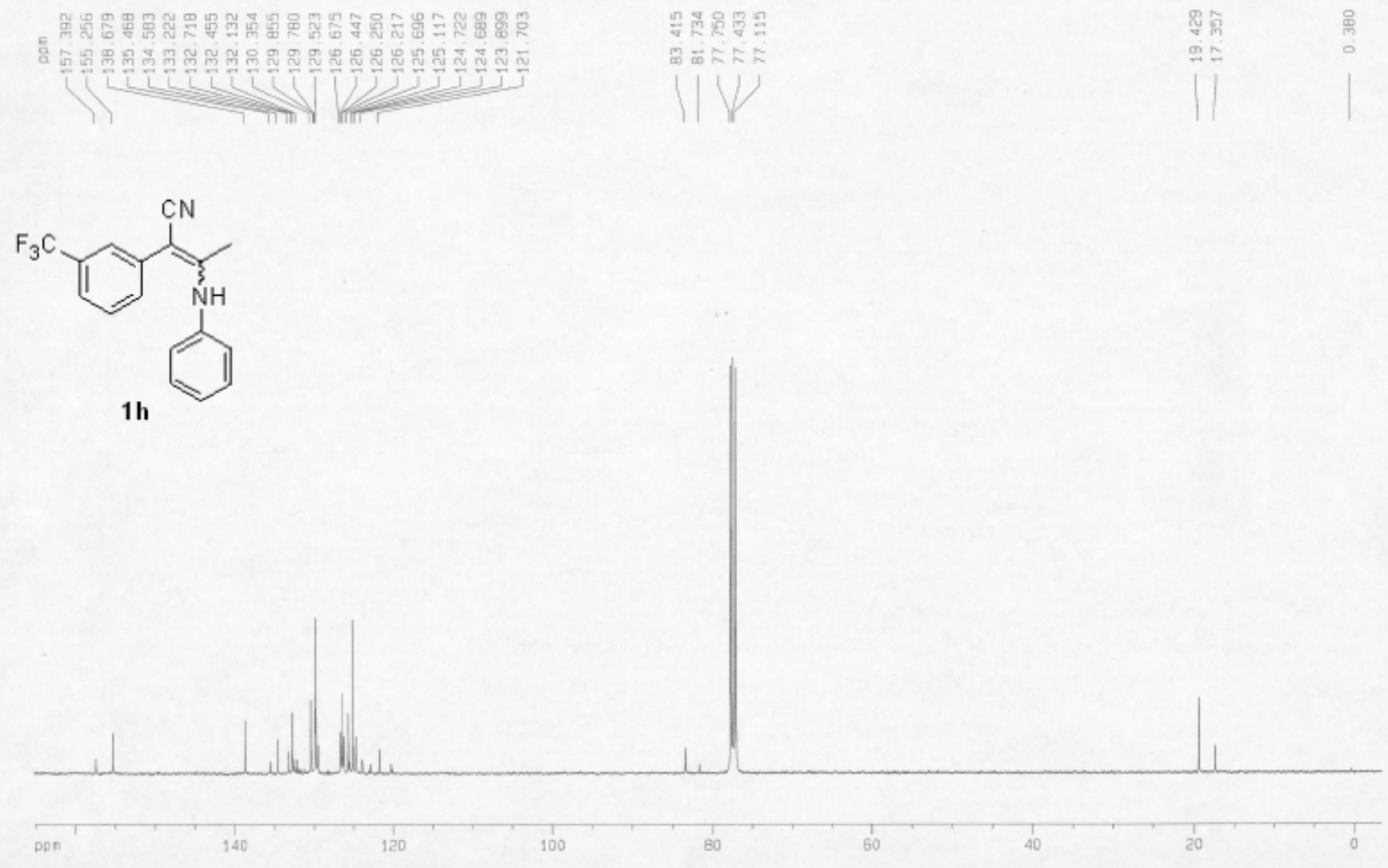

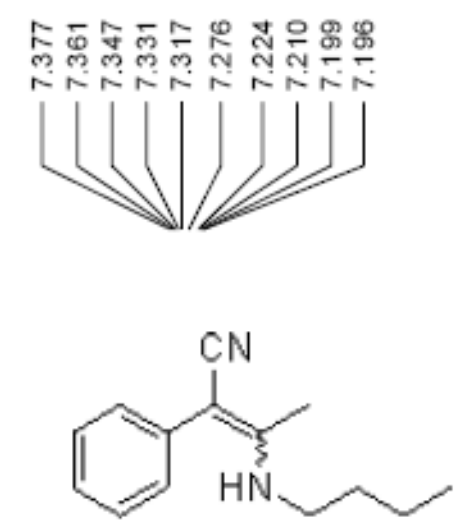

$1 i$

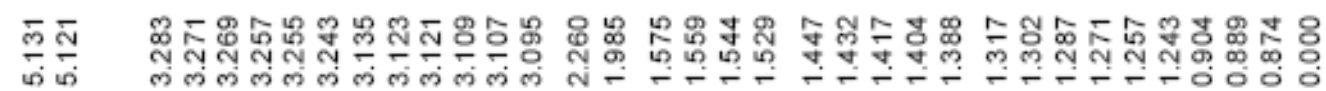
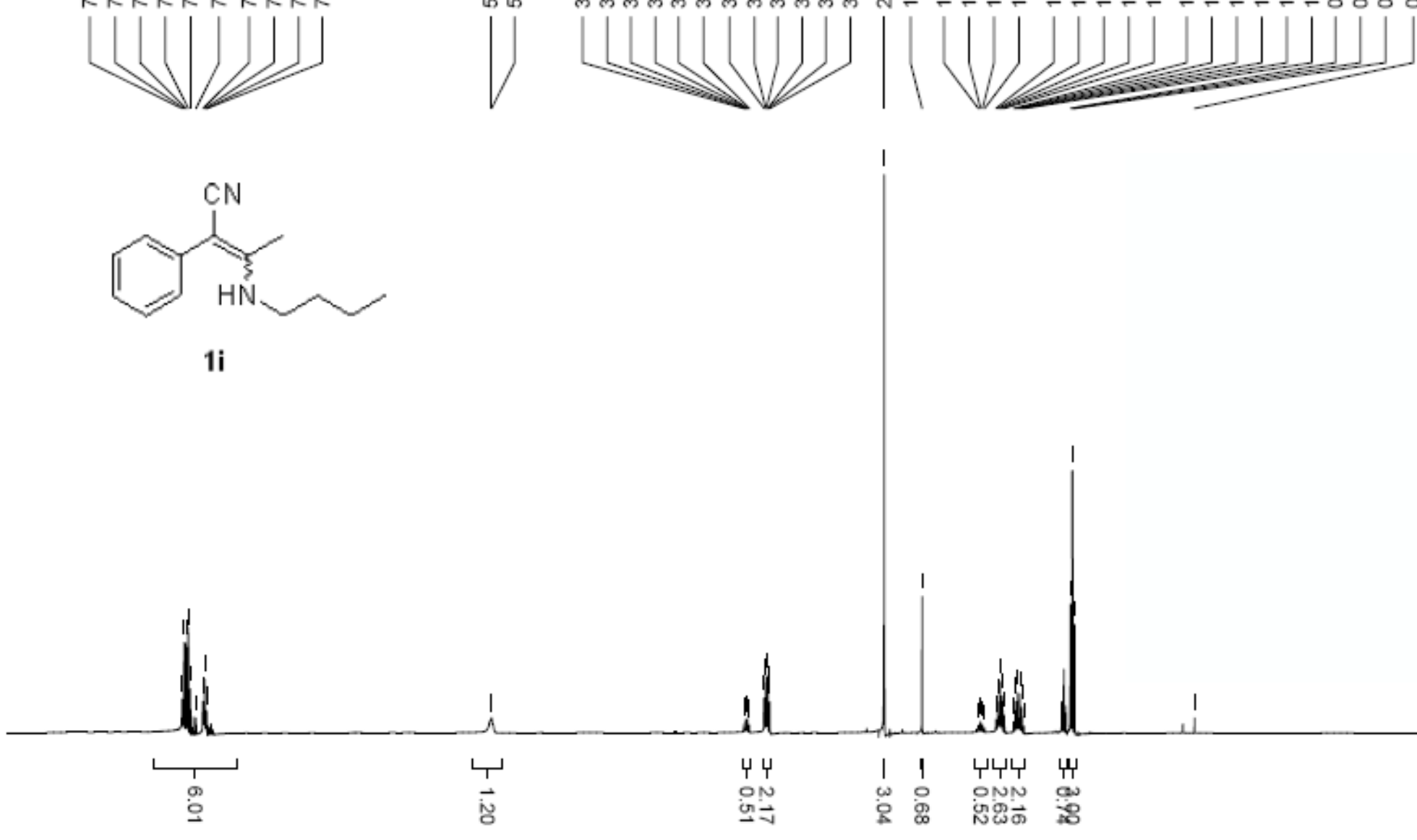

$\mathrm{ppm}(\mathrm{f} 1)$ 


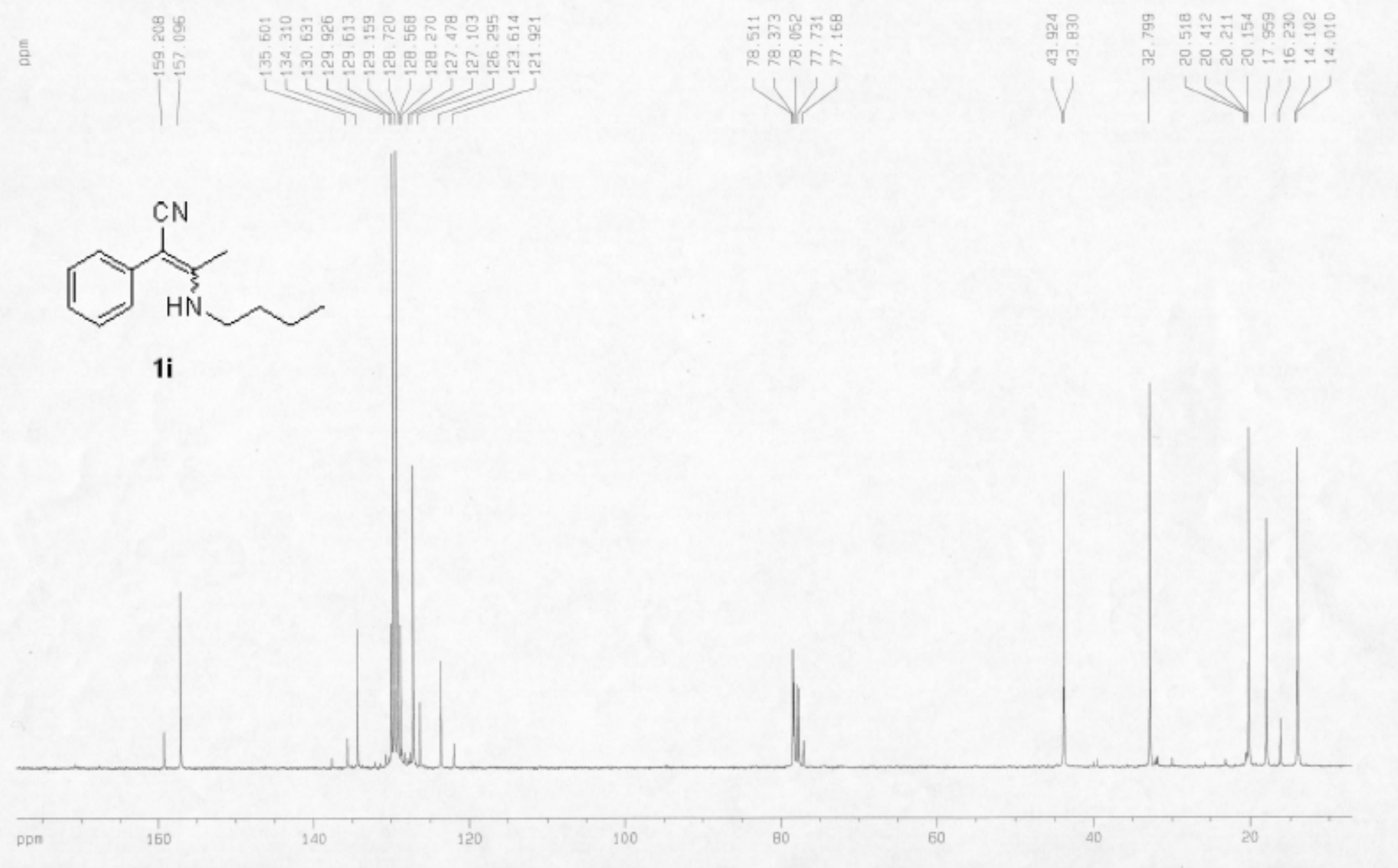




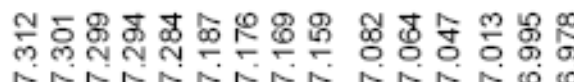

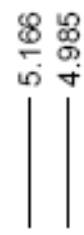

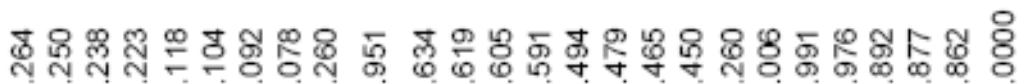

$\stackrel{8}{\stackrel{\leftrightarrow}{\circ}}$

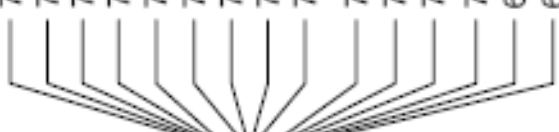
वृलm

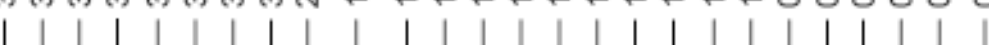<smiles>CCCN/C(C)=C(\C#N)c1ccc(F)cc1</smiles>

$1 \mathrm{j}$

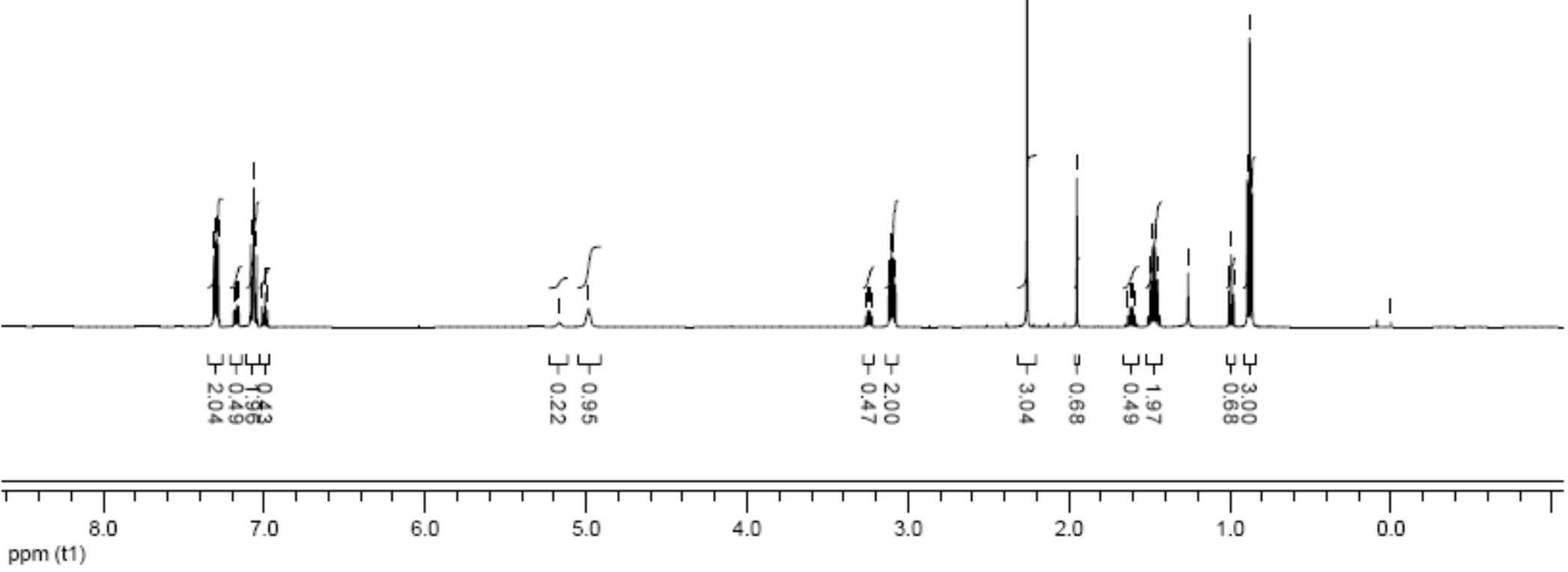



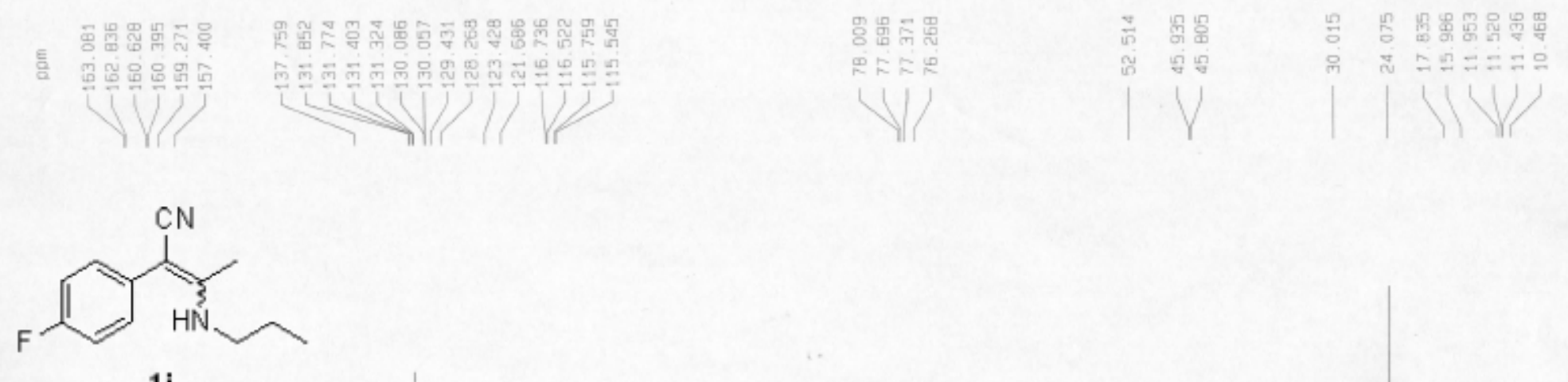

1j

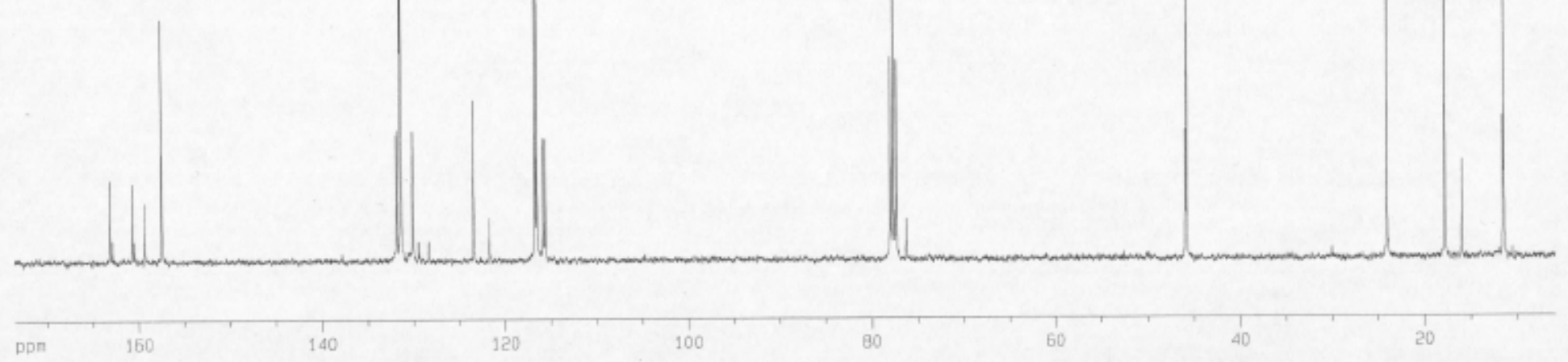

